\title{
Textos
}





\section{Teologia e Messianismo no pensamento de W. Benjamin*}

JEANNE-MARIE GAGNEBIN

Para Irving Woblfarth

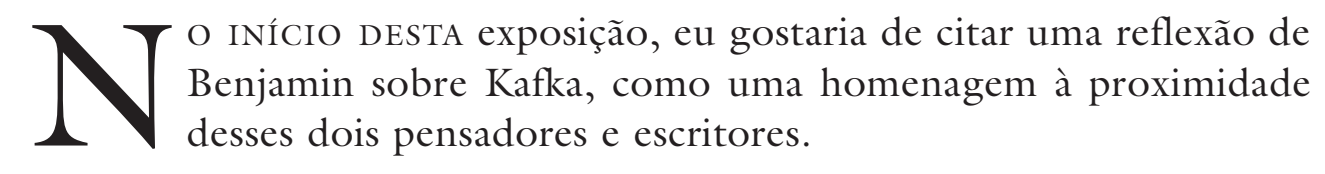

“Já puderam perceber que, em toda a obra de Kafka, o nome 'Deus' não aparece. E nada há mais vão do que introduzi-lo na interpretação dessa obra. Quem não entende o que pró́be a Kafka usar esse nome não entende uma linha sequer deste autor" (1).

Tal observação deve nos servir como sinal de prudência: nos caminhos das diversas interpretações da obra de Walter Benjamin, os motivos teologia e messianismo acabam se tornando armadilhas perigosas, até porque, muitas vezes, remetem à louvável intenção de reconciliar aspirações religiosas e lutas políticas. Eu gostaria, nesta comunicação, de enunciar algumas hipóteses de leitura que acenam para outra direção. Desde já, posso adiantar que tais hipóteses se baseiam numa distinção conceptual, a meu ver esclarecedora para a leitura da obra de Benjamin, e que me parece ter sido geralmente preterida pela literatura secundária: a distinção entre religião e teologia.

Convém começar por uma breve evocação histórica do modo pelo qual foi recebida a obra de Benjamin. Ele ainda em vida, seus amigos já divergem sobre a orientação verdadeira de seu pensamento. Enquanto Gershom Scholem vê nele um dos últimos representantes da autêntica tradição mística judaica e o censura por se deixar desviar de sua essência verdadeira por contingências históricas e amorosas (especialmente pelos

* Este texto é a tradução de uma palestra proferida em Milão, em 3 de novembro de 1998, por ocasião do Colóquio Millenarismi nella cultura contemporanea, organizado pelo Centro di studi del pensiero filosofico del'500 e del'600 in relazione ai problemi della scienza - CNR e pelo Centro di Judaica GorenGoldstein, da Universidade de Milão. 
perversos encantos de Asja Lacis, aquela comunista letã!), os amigos que militam no partido comunista, como Brecht ou a própria Asja, lamentam a indecisão política e existencial de Benjamin, pedindo-lhe que assuma sua condição de pensador materialista. No meio, por assim dizer, Adorno (e, em menor grau naquela época, Horkheimer), que é sensível à inspiração teológica dos escritos de Benjamin, tanto quanto ao esforço de construção de uma teoria materialista da cultura e da História, mas critica, em várias oportunidades, a falta de dialética de tais tentativas. Discussões semelhantes iriam surgir com força redobrada na ocasião da redescoberta de Benjamin, nas décadas de 60 e 70, com a renovação do movimento estudantil.

Lido como um dos primeiros teóricos da esquerda que havia questionado o determinismo economicista e político da Segunda Internacional, Benjamin tornou-se o emblema de um pensamento autenticamente político e materialista, porém, antideterminista e antitotalitarista. É importante essa interpretação e eu a considero válida até hoje. Teve ela, no entanto, grande dificuldade em acolher os elementos messiânicos e teológicos espalhados pela obra do filósofo, particularmente no seu último texto, as célebres Teses sobre o conceito de História (2).

Obra póstuma - pode-se duvidar que Benjamin a teria publicado na forma em que a deixou escrita, pois sabia muito bem que essas teses teriam sido fonte de inúmeros mal-entendidos (3) -, é um texto fulgurante que deve justamente seu brilho à junção, perigosa e esplêndida, de motivos materialistas e marxistas com temas teológicos e messiânicos. A primeira tese já trata, de modo enigmático, da estreita relação que, segundo Benjamin, deve unir o materialismo histórico e a teologia. Leio agora essa tese, à interpretação da qual voltaremos no fim desta exposição.

"Como se sabe, deve ter havido um autômato, construído de tal maneira que ele, a cada jogada de um enxadrista, respondia com uma contrajogada que lhe assegurava a vitória da partida. Diante do tabuleiro, que repousava sobre uma ampla mesa, sentava-se um boneco em trajes turcos, com um narguilé na boca. Um sistema de espelhos despertava a ilusão de que essa mesa era transparente de todos os lados. Na verdade, um anão corcunda, mestre no jogo de xadrez, estava sentado dentro dela e conduzia por fios a mão do boneco. Pode-se imaginar na filosofia uma contrapartida dessa aparelhagem. O boneco chamado 'materialismo histórico' deve ganhar sempre. Ele pode medir-se, sem mais, com qualquer adversário, desde que tome a seu serviço a teologia, que, hoje, sabidamente, é pequena e feia e que, de toda maneira, não deve deixar-se ver" (4). 
Como podem imaginar, os espíritos se dividiram rapidamente quando se tratou de explicar uma imagem tão estranha. Para Scholem, a comparação indica nitidamente que a teologia rege a História e deve reger o materialismo histórico, uma vez que o pequeno anão, escondido por certo, porém jogador soberano, é quem manipula os fios que comandam os movimentos do autômato. No lado oposto, para Hans Dieter Kittsteiner, no tão citado número da revista berlinense de esquerda, Alternative, consagrado já em outubro de 1967 a Benjamin, tratar-se-ia muito mais de fazer da teologia uma ancilla philosophiae, ou melhor, uma serva do materialismo histórico que a toma a seu serviço, como afirma a tese (5).

Tais interpretações desencontradas dos adeptos de um Benjamin materialista e de outro, místico-teológico, haveriam felizmente de ser aos poucos substituídas por estudos de conjunto sobre o autor. Assim como o têm notado muitos comentadores (6), sob a diversidade dos temas e dos estilos, o pensamento de Benjamin é, no entanto, atravessado, já em suas obras de juventude e ainda nos fragmentos do Passagenwerk, por determinados motivos-chaves: a desconfiança para com a tradição afirmativa burguesa, a preocupação com o singular, o detalhe, os fenômenos estranhos e extremos contra a média niveladora (7), enfim, reunindo essas duas primeiras características, uma concepção da interpretação e da história acompanhada por uma vontade soteriológica, um desejo de memória e preservação dos elementos preteridos e esquecidos pela historiografia burguesa, sempre apologética: os excluídos e vencidos, mas também o não-clássico, o não-representativo, o estranho, o barroco etc. Essa teoria herética e iconoclasta do conhecimento é amparada, sempre de acordo com tais intérpretes, em uma concepção lingüística de origem teológica que opõe à arbitrariedade do signo a existência de uma língua originária, na qual, respondendo ao verbo criador de Deus, o homem nomeia o mundo com justeza. Essa língua adâmica, tal como a descreve o ensaio de 1916, Über Sprache überhaupt und über die Sprache des Menschen, já não existe hoje; não está, porém, totalmente perdida. Sua presença subterrânea continua habitando, idealmente, a multiplicidade de nossas diversas línguas, manifestando-se em particular na dupla operação, ao mesmo tempo de distanciamento e aproximação, em que se constituem a tradução e a crítica (8), assim como, aliás, nos esforços, vãos e sempre renovados, dos filósofos e dos poetas para dizer verdadeiramente o mundo. Portanto, teríamos em Benjamin, sempre na opinião desses intérpretes, um esquema teórico que reformularia, de modo extremamente original, é verdade, um paradigma de origem religiosa: a história humana seria a perda de um paraíso originário determinada pela queda na temporalidade e na incomunicabilidade (Babel, como consa- 
gração lingüística do pecado original); a transformação dessa história decaída e o restabelecimento da harmonia primitiva seriam assim a única tarefa autêntica na qual os homens se devem empenhar, por uma prática (revolucionária) ou/e por uma teoria reparadora da injustiça.

Essa interpretação da obra de Benjamin oferece muitas vantagens. Possibilita uma apreensão global do pensamento do filósofo ao introduzir diferenciações úteis em vez de estabelecer uma separação categórica entre um Benjamin moço, idealista e místico, e um Benjamin de idade madura, materialista e marxista. É uma leitura que tem igualmente o grande mérito de afirmar que convicções políticas de esquerda, até marxistas, e convicções religiosas não se excluem necessariamente mas, ao contrário, podem fortalecer-se mutuamente. Toda a obra de Michael Löwy enfatiza essa leitura. Finalmente, tal convergência contribui de modo salutar a fragilizar a redução positivista do fenômeno religioso ao irracional, em oposição ao político como esfera do desdobramento da razão (9).

Gostaria, no entanto, de apontar algumas questões que esta leitura de Benjamin, segundo um paradigma fundamentalmente religioso, me parece levantar, propondo em seguida, no intuito de elucidar melhor o assunto, uma distinção entre os paradigmas religioso e teológico, em especial na obra de Benjamin.

Em primeiro lugar, cumpre observar que a transformação do texto de juventude Über Sprache überhaupt und über die Sprache des Menschen (Sobre a lingua em geral e sobve a lingua do homem), particularmente a leitura de Gênesis nele proposta, em uma espécie de descrição filosóficohistórica e filosófico-lingüística de um paraíso perdido que teria realmente existido e em busca do qual a humanidade continua se empenhando, é uma transformação contestável. O próprio Benjamin salienta que o ato de recorrer ao texto de Gênesis não tem a finalidade de esboçar uma reconstrução histórica (10), antes visa lembrar outra compreensão da linguagem humana, compreensão quase esquecida, até mesmo repelida pela hipótese lingüística da arbitrariedade do signo e da comunicação como função primordial da linguagem. A importância do texto de Gênesis vem do fato que ele nos faz recordar a outra função da linguagem humana, função verdadeiramente essencial, a de nomear, que não se pode explicitar nem em termos de comunicação nem em termos de arbitrariedade. Convém observar que o tema da denominação volta freqüentemente na obra de Benjamin, seja indicando o ideal - inacessível - da linguagem filosófica no Prefácio ao livro sobre o drama barroco (11), seja evocando o fundamental impulso mimético humano na tentativa materialista de descrever a origem da linguagem (12), ou ainda aludindo ao nome verdadeiro 
dado às escondidas à criança na tradição judaica (13). Dessa forma, se é verdade que existem no pensamento de Benjamin liames essenciais entre língua e história, conforme ressalta Giorgio Agamben em notável artigo (14), parece-me discutível ler os textos de teoria da linguagem como se fossem textos de filosofia da história tratando das origens lingüísticas e históricas da humanidade.

É preciso também confessar que os intérpretes são tomados de um certo mal-estar, quando se trata de compreender, partindo do paradigma religioso, o estatuto da história humana, material, concreta, no pensamento de Benjamin. Usando um tom provocativo, poderíamos nos perguntar por que Benjamin lhe teria atribuído tamanha importância e dedicado tantos trabalhos, se essa mesma história devesse ser, na realidade, tão somente uma espécie de parêntese infeliz entre o Paraíso (perdido) e sua última restauração (15).

Enfim e acima de tudo, o argumento decisivo que nos impele a rever com máxima seriedade essa aplicação do paradigma religioso ao pensamento de Benjamin é a insistência de determinados textos na separação rigorosa entre a esfera do religioso e a do político. O texto mais decisivo a esse respeito é o Fragmento teológico-político (assim denominado por Adorno) que data dos anos 20, e deve ser recolocado no contexto de uma dupla discussão, a de Benjamin com seus amigos sionistas (Scholem emigra para a Palestina em 1924) e, igualmente, com certo marxismo, em particular com o livro de Ernst Bloch, publicado em 1918, Geist der Utopie (Espírito da utopia). O referido fragmento é objeto de uma análise pormenorizada no livro recente de Gérard Raulet (16), mas já havia sido esplendidamente interpretado por Irving Wohlfarth em 1986 (17), em artigo que me parece fundamental (e que, aparentemente, Raulet não conhece: pelo menos nunca o menciona). Tomo a liberdade de citar o início desse fragmento:

“O próprio Messias, apenas ele, é que perfaz todo o advir histórico, no sentido que só ele liberta, cumpre, leva ao cabo a sua relação com o próprio messiânico. Eis por que nada de histórico pode, por vontade própria e por si mesmo, querer se referir ao messiânico. Eis por que o Reino de Deus não é o telos da dinâmica histórica; ele não pode ser posto como meta. Visto historicamente, ele não é meta, mas fim. Eis por que a ordem do profano não pode se edificar segundo o pensamento do Reino de Deus, eis por que a teocracia não tem nenhum sentido político, mas tão-somente um sentido religioso. Ter negado com toda a intensidade possível a significação política da teocracia é o grande mérito de O Espírito da utopia de Bloch" (18). 
Não disponho infelizmente de mais tempo para prosseguir na leitura desse texto, mas creio que seu primeiro parágrafo já nos proporciona uma preciosa indicação: o Reino de Deus não é a meta (telos ou Ziel), mas o fim (Ende) da dinâmica histórica. Benjamin haveria de retomar essa afirmação, é importante dizer, bem mais tarde, em uma das observações redigidas na ocasião das teses Sobre o conceito de História: "O Messias interrompe a História; o Messias não surge no final de um desenvolvimento" (19). Aparece aí uma crítica da concepção de um vir-a-ser histórico (profano), cuja apoteose seria a vinda do Reino de Deus e, de maneira simultânea ou sinônima, a do Reino da Liberdade (o Reich der Freiheit de Marx). O mesmo esquema religioso de esquerda (seja ele sionista ou/e socialista) é afastado em benefício de uma distinção entre a ordem das metas (a propalada questão da teleologia na história), que é a ordem do profano e do político, e a instância do fim da história - Benjamin dirá, com mais radicalidade ainda nas Teses, de sua interrupção, instância teológica e messiânica. Se é verdade que existe uma relação entre uma e outra ordem, ela não remete a nenhuma concordância preestabelecida, mas, antes, a uma espécie de acúmulo de forças opostas segundo descreve a seqüência do fragmento.

Aqui é que gostaria de introduzir uma distinção conceptual entre o religioso e o teológico. Defendo, pois, a hipótese de que o pensamento de Benjamin foi profundamente marcado, impregnado, como ele mesmo o diz, por motivos oriundos da tradição teológica, antes de tudo judaica mas também cristã (ver a célebre noção de apokatastasis de Orígenes citada por Benjamin em várias ocasiões); em contrapartida, esse seu pensamento mantém uma distância crítica importante com relação à religião e ao religioso. Podemos inicialmente nos satisfazer com uma definição tradicional de religião de acordo com a etimologia (religio), como um “conjunto de doutrinas e práticas" (Littré) que visa à integração do homem no mundo, sua ligação com ele, isto é, antes de tudo, a aceitação do sofrimento e da morte por meio do reconhecimento de um sentido transcendente.

Benjamin tratou do fenômeno religioso em vários textos de sua juventude, em especial: Dialog über die Relogiosität der Gegenwart (20) e Kapitalismus und Religion (21). Mais tarde, porém, o vocábulo desaparece quase totalmente, enquanto o tema teologia assume uma importância crescente. Poderíamos dizer, como já o fizeram muitos comentadores (22), que o interesse do jovem Benjamin pelo fenômeno religioso se deve a sua leitura de Max Weber e a seu entusiasmo, muito comum na época, por Nietzsche. No fragmento Capitalismo e religião, por exemplo, 
as mais importantes características da Religião são os conceitos de Schuld (dívida, culpa) e de culto, o primeiro eminentemente nietzschiano, o segundo tomado a Simmel, outro modelo intelectual do jovem Benjamin, tudo isso no contexto weberiano da ligação entre protestantismo e capitalismo. Benjamin foi assimilando a temática, discutida na época, por meio de duas noções fundamentais: o desencantamento do mundo de Max Weber e a morte de Deus de Nietzsche, duas noções das quais, no mínimo, não se pode afirmar que elas reforçam um paradigma positivo do religioso! Aliás, em numerosos textos, Benjamin ataca os substitutos religiosos medíocres que, como Max Weber já o havia bem percebido, proliferam em períodos de desencantamento, quando as grandes religiões desmoronam.

Benjamin salienta a necessidade de o pensamento, e especialmente o pensamento político, enfrentar a árida grandeza do profano sem o consolo ou o confor to de um Ersatz (substituto) de religião. A esse respeito, poderíamos citar os mais diversos textos, tais como Experiência e pobre$z a$, vários ensaios, um sobre o surrealismo, outros sobre Kafka, e todos os textos que versam sobre a perda da aura, desde os escritos de Baudelaire até $A$ obra de arte na era de sua reprodutibilidade técnica.

Não seria também por causa da morte de Deus nietzschiana e do desencantamento weberiano que a própria teologia - uma figura diferente da religião, como vamos verificar - não pode comportar nada que seja triunfante ou grandioso? Ela é, segundo a célebre imagem da primeira tese Sobre o conceito de História, "pequena e feia", não ousa se manifestar, mas, no entanto, permanece indispensável. Essa teologia nanica e encolhida se parece, qual uma irmã, com certas figuras de Kafka (ainda ele), com os anjos efềmeros, carentes e verídicos que cintilam em muitos textos de Benjamin (23), e sobretudo, com o "pequeno corcunda" da Infância berlinense, aquele que se lembra daquilo que esquecemos e acompanha atentamente todos os nossos tropeços (24). Uma teologia humilde, discreta, quase evanescente e, no entanto, firme na sua fragilidade. Essas mesmas propriedades a caracterizam numa célebre observação de nosso autor, escrevendo sobre o próprio pensamento, e que se encontra justamente no aparato crítico das Teses. Benjamin escreve:

"Meu pensamento se comporta com a teologia da mesma forma que o mata-borrão com a tinta. Ele fica totalmente embebido dela. Mas se fosse seguir o mata-borrão, então nada subsistiria daquilo que está escrito" (25). 
Temos aqui a descrição de um pensamento que absorveu a tal ponto os ensinamentos da teologia que o texto sagrado original torna-se dispensável. Como se a tinta da primeira página tivesse sido totalmente apagada e só ficasse para nós a constelação de manchas e sinais, constelação que, segundo a analogia de Benjamin, deveria ser suficiente, sem possibilidade de volta ao texto primitivo. Essa comparação, muito bela, mas também burlesca e um tanto inquietadora, leva-me a fazer duas observações: a primeira, sobre a importância do profano no pensamento de Benjamin; a segunda sobre o complexo metafórico texto/escrita.

Poderíamos dizer, de forma jocosa, que, em Benjamin, a importância da noção de profano não tem igual a não ser a de sagrado - da qual ele fala muito pouco. Assim como a tinta é absorvida definitivamente pelo mata-borrão, do mesmo modo, em Benjamin, as figuras teológicas e messiânicas comprovam sua eficácia suprema ao serem, por assim dizer, totalmente absorvidas, até desaparecerem, pelo mundo profano. Esse profano embebido de sagrado é o irmão da prosa libertada (26), que será a do mundo messiânico, de acordo com vários fragmentos da época das Teses. Da mesma maneira, como essa prosa teria integrado em si própria todas as línguas e gradações retóricas, do estilo mais baixo ao mais elevado. Assim também, no dizer do Fragmento teológico-politico, o Messias liberta; resolve (erlöst) o "advir histórico" porque leva até o fim sua relação com o messiânico como tal, "leva ao cabo sua relação com o próprio messiânico". Em outras palavras, o Messias só virá no momento em que tiver conseguido tornar-se dispensável. Tal Messias não vem para instaurar seu Reino, ao mesmo tempo consecutivo ao reino terrestre e diferente dele. Ele vem justamente "quando já não se precisa dele, virá um dia depois de sua chegada, não virá no último dia, mas no derradeiro", como escreve também Kafka, ainda ele (27). O Messias chega, portanto, quando sua vinda se realizou tão integralmente que o mundo já não é profano nem sagrado, mas liberto - liberto sobretudo da separação entre profano e sagrado. Cabe lembrar aqui que os termos Erlösung, erlösen, Erlöser remetem ao radical lös (no grego antigo luein, livrar ou desatar como o faz Dionisios, o lusos, que desata os laços de ordem sexual ou familiar), indica a dissolução, o desfecho, a resolução ou solução de um problema, por exemplo, por seu desaparecimento bem-vindo. A redenção (Erlösung), em Benjamin, não se confunde, portanto, com a Aufhebung hegeliana baseada em uma Erinnerung integradora infinita, nem mesmo com a idéia, tão importante, de uma salvação ou conservação (Rettung) do passado pelo trabalho necessário do historiador e a prática da rememoração (Eingedenken). Se a redenção livra, é porque ela destrói e dissolve, não porque mantém e conserva (28). E o Messias nos livra justamente da 
oposição entre o histórico e o messiânico, da oposição entre o profano e o sagrado. É por essa razão que, no mesmo Fragmento teológico-político, a ordem do profano, que deve ditar a ordem política, é orientada pela idéia da felicidade. Neste sentido bem preciso, poderíamos dizer que, realmente, em Benjamin, a realização messiânica é também a realização da felicidade terrestre. Não porque fé religiosa e convicções políticas atuariam no mesmo sentido e em direção à mesma meta (telos), mas porque a atualidade messiânica não se pode enunciar a não ser na prosa libertada, livrada, do mundo terrestre (29).

Walter Benjamin

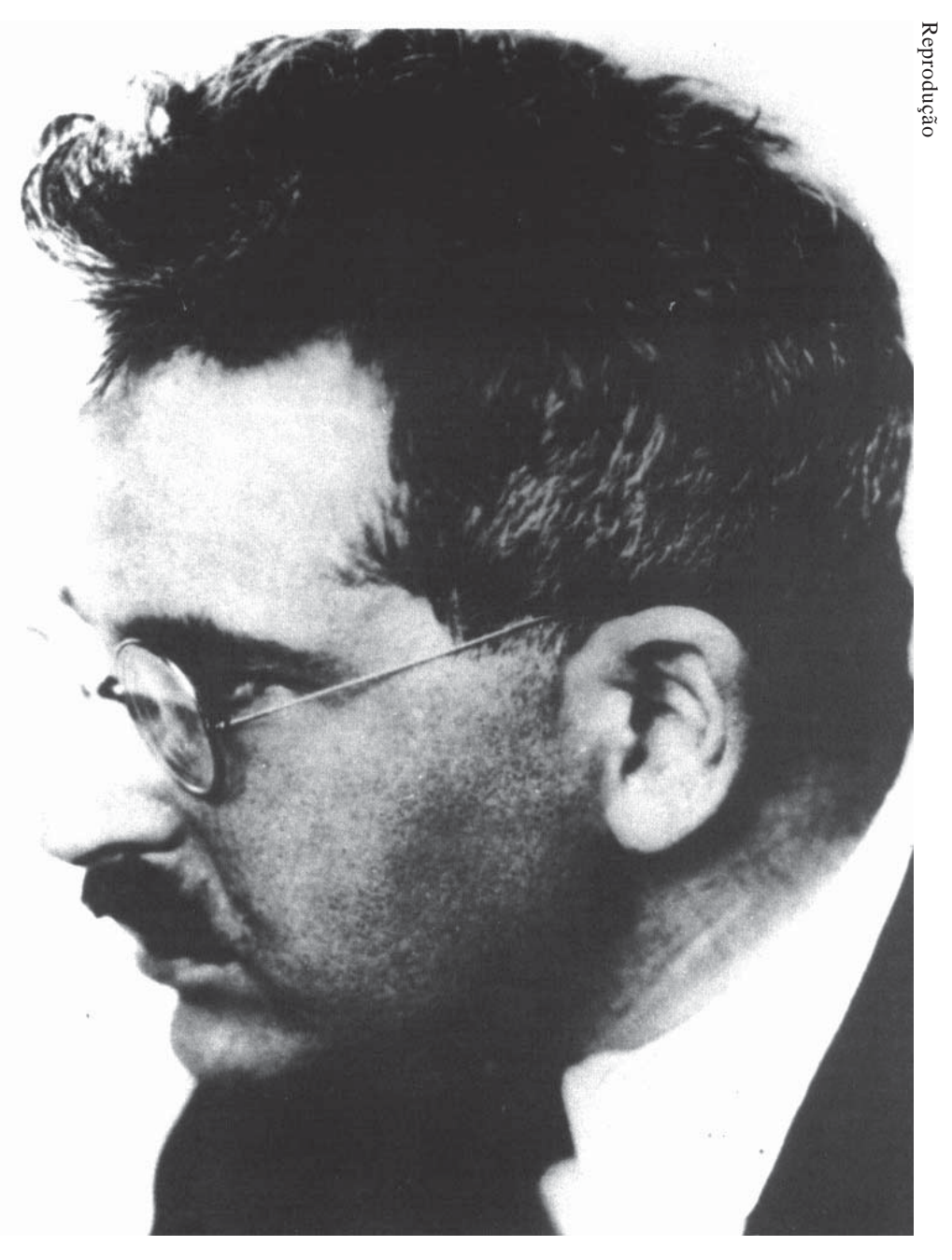

A metáfora do mata-borrão e do texto remete igualmente à relação essencial entre teologia e escritura, teologia e texto primitivo - mas, aqui, dispensável, ou até mesmo desaparecido. Benjamin se inscreve aqui na 
tradição da Cabala (30) e também na proximidade especulativa de Kafka e Borges, sem falar de Derrida. A metáfora convida-nos a pensar no estatuto epistemológico muito particular do tipo de discurso chamado teologia. Como ressaltaram inúmeros pensadores, a teologia não é, em primeiro lugar, uma construção especulativa dogmática, mas, antes e acima de tudo, um discurso profundamente paradoxal: discurso ou saber (logos) "sobre" Deus (theos), consciente, já no início, de que o "objeto" visado lhe escapa, por ele se situar muito além (ou aquém) de qualquer objetividade. Assim, a teologia seria o exemplo privilegiado da dinâmica profunda que habita a linguagem humana quando essa se empenha em dizer, de verdade, seu fundamento, em descrever seu objeto e, não o conseguindo, não se cansa de inventar novas figuras e novos sentidos. Por certo, nem todos os discursos humanos seguem a regra de uma impossibilidade transcendental e constitutiva de apreender o próprio objeto. Mas tal paradigma de um discurso que se definiria por sua insuficiência essencial, constituindo-se positivamente em redor dessa ausência - um paradigma oriundo da teologia -, habita no cerne da tradição filosófica e poética, especialmente contemporânea. Convém observar, aliás, que, se Deus é o primeiro e, talvez o mais radical, desses significados insondáveis e indizíveis, ele não é o único. Nem a beleza do mundo nem o sofrimento humano podem verdadeiramente ser ditos - Michael Rinn abordará provavelmente esse tema na sua exposição.

O uso correto da teologia lembraria assim, contra a hybris dos saberes humanos, que nossos discursos são incompletos e singulares, e vivem dessa preciosa fragilidade. Seria o caso de citar Paul Ricoeur afirmando com força que a função do referente "Deus" não é a de oferecer uma solução a questões insolúveis: ele é, muito mais, o "ponto de fuga, o índice de incompletude de (...) discursos parciais” (31).

O mesmo conceito de teologia parece-me guiar a reflexão de Benjamin, quando, no prefácio do livro sobre o drama barroco, ele compara a escrita filosófica com os tratados teológicos medievais, afirmando terem eles em comum o esforço de uma "exposição/apresentação (Darstellung) da verdade", isto é, uma retomada sem fim, um caminhar sempre reiniciado, uma multiplicidade de percursos. O surgimento e desaparecimento dessas voltas (32) se dá em oposição à linha reta do método geométrico, do ideal cartesiano do conhecimento, o qual se apodera do objeto que tencionava alcançar. A uma filosofia concebida como doutrina do conhecimento ou como o próprio conhecimento de um objeto preciso por um sujeito determinado, Benjamin opõe, na esteira da metafísica platônica e da teologia, a outra vertente da busca filosófica: uma errância 
(errance) fértil, um exercício paciente que não visa possessão alguma mas procura desenhar, expor, de modo lúdico ou grave, e sempre incompleto, aquilo que simultaneamente, fundamenta o logos e a ele escapa. A tradição filosófica lhe dá também outro nome: verdade (33). Nesse sentido, no pensamento de Benjamin, o paradigma teológico não funciona como aquilo que propiciaria uma resposta (religiosa) às perguntas dos homens; antes seria, pelo contrário, o que abala os edifícios, tão bem construídos, dos sistemas lógicos, especulativos ou políticos. Aí também, o caráter destruidor benjaminiano está agindo para preservar a possibilidade da salvação. Nessa mesma ótica de uma desestabilização redentora, é que proporia ler a declaração muito conhecida e tão freqüentemente interpretada como uma confissão de fé:

"E se é que o devo exprimir em uma só palavra: nunca pude buscar e pensar de outra forma, se assim ouso dizer, que não em sentido teológico, isto é, de acordo com a doutrina talmúdica dos 49 graus de sentido de cada passagem da Torá (34). Bem: hierarquia de sentido é o que possui, segundo minha experiência, a mais repisada pletitude comunista, mais que a profundeza burguesa atual que continua limitada ao sentido da apologética” (35).

Exclamação essa que nos remete à estranha aliança que une a boneca "materialismo dialético" e o anãozinho "teologia" na primeira das Teses sobre o conceito de História. No âmbito mais amplo desse último texto de Benjamin, o de uma luta renhida contra a ideologia do progresso que impede as forças de esquerda, em especial, a social-democracia alemã, de combater o fascismo, a teologia cumpre o papel de salutar antídoto contra as "crenças" de boa parte do proletariado e da esquerda: ou seja, acreditavam estar caminhando "no sentido do curso" (36) da história, no sentido de um progresso inelutável que o fascismo, simples episódio infeliz, não conseguiria deter. Ou então, dito com outras palavras: um pouco mais de teologia poderia ajudar as forças de esquerda a se livrar de suas funestas tendências a reconstruir uma religião - entendida ali no sentido restrito de sistema de crenças fundamentado na certeza de um sentido desde já dado e assegurado, ao passo que há pelo menos 49 graus de sentido.

Não é necessário dizer que dessa teologia continuamos precisando. Pelo menos, diria talvez Benjamin, até o Messias interromper a história e livrar, dissolver, resolver (er-lösen) o antagonismo do profano e do sagrado. 
1 "Es wurde darauf hingewiesen, dass im ganzen Werk Kafkas der Name 'Gott' nicht vorkommt. Und nichts ist müssiger als in seiner Erläuterung ihn einzuführen. Wer nicht versteht, was Kafka den Gebrauch dieses Namens verbietet, versteht von ihm keine Zeile" (Walter Benjamin, Gesammelte Schriften II-3, p.1219. Tradução de J.M.G.). De agora em diante, as citações serão tiradas dessa edição publicada a partir de 1974 pela Editora Suhrkamp.

2 Über den Begriff der Geschichte, in G.S. I-2, p.693-704. O texto foi inicialmente publicado com o título de Geschichtsphilosophische Thesen nos primeiros escritos de Benjamin publicados na ed. Suhrkamp antes da edição crítica. Por isso é com freqüência citado, simplesmente, como Teses.

3 Ver a carta de Benjamin a esse respeito, dirigida a Gretel Adorno, G.S. I-3, p. 1223.

4 "Bekanntlich soll es einen Automaten gegeben haben, der so konstruiert gewesen sei, dass er jeden Zug eines Schachspielers mit einem Gegenzuge ewidert habe, der ihm den Gewinn der Partie sicherte. Eine Puppe in türkischer Tracht, eine Wasserpfeife im Munde, sass vor dem Brett, das auf einem geräumigen Tisch aufruhte. Durch ein System von Spiegeln wurde die Illusion erweckt, dieser Tisch sei von allen Seiten durchsichtig. In Wahrheit sass ein buckliger Zwerg darin, der ein Meister im Schachspiel war und die Hand der Puppe an Schnüren lenkte. Zu dieser Apparatur kann man sich ein Gegenstück in der Philosophie vorstellen. Gewinnen soll immer die Puppe, die man 'historischen Materialismus' nennt. Sie kann es ohne weiteres mit jedem aufnehmen, wenn sie die Theologie in ihren Dienst nimmt, die heute bekanntlich klein und hässlich ist und sich ohnehin nicht darf blicken lassen" (G.S. I-2, p. 693). Tradução [manuscrito] de J.M. Gagnebin e M. LutzMüller.

5 H.D. Kittsteiner, Die 'Geschichtsphilosophischen Thesen', in Alternative, Berlim, n. 56-57, p. 245, out./dez, 1967.

6 Citarei principalmente, apesar de suas respectivas diferenças, muitas vezes importantes, Irving Wohlfarth, Michael Löwy e Stéphane Mosès. Na Alemanha, Bernd Witte e Winfried Menninghaus.

7 Em artigo fundamental, Carlo Guinsburg mostra como certa epistemologia do excêntrico revelou-se fecunda para as ciências humanas contemporâneas de Warburg até Freud. Evidentemente, eu acrescentaria W. Benjamin. Ver Guinsburg, Miti emblemi spie: morfologia e storia, Einaudi, 1986.

8 Ver sobretudo Die Aufgabe des Übersetzers, G.S. IV-1. 
9 Cabe observar que certas críticas de peso ao pensamento de Benjamin originam-se exatamente da junção entre instância salvadora e instância crítica materialista em sua filosofia da História. É, sem dúvida, o caso de Habermas em seu artigo de 1972, Bewusstmachende oder rettende Kritik: die Aktualität Walter Benjamin, in Zur Aktualität Walter Benjamins, Suhrkamp, 1972, e, mais recentemente, o de Rainer Rochlitz, em Le désenchantement de l'art, la philosophie de Walter Benjamin, Gallimard, 1992.

10 "Wenn im folgenden das Wesen der Sprache auf Grund der ersten Genesiskapitel betrachtet wird, so soll damit weder Bibelinterpretation als Zweck verfolgt noch auch die Bibel an dieser Stelle objektiv als offenbarte Wahrheit dem Nachdenken zugrunde gelegt werden, sondern das, was aus dem Bibeltext in Ansehung der Natur der Sprache sich ergibt, soll aufgefunden werden". Über Sprache überhaupt und über die Sprache des Menschen, in G.S. II-1, p. 147.

11 Erkenntniskritische Vorrede in Ursprung des deutschen Trauerspiels, G.S. I1, p. 216-217.

12 Ver os dois textos vizinhos: Lehre des Ähnlichen e Mimetisches Vermögen, in G.S. II-1, p. 204-213.

13 Ver o estranho texto Agesilaus Santander e a interpretação de Scholem, Walter Benjamin und sein Engel, in Zur Aktualität Walter Benjamins, Suhrkamp, 1972.

14 Langue et Histoire. Catégories historiques et catégories linguistiques dans la pensée de Benjamin, in Walter Benjamin et Paris, Cerf, 1986.

15 Sente-se esse mal-estar no artigo de Stéphane Mosès, L'idée d'origine chez Walter Benjamin, in Walter Benjamin et Paris, ibid., no qual a categoria de Ursprung é entendida, antes de tudo, como uma origem primeira e imaculada, que o fim dos tempos - da história - teria como meta restabelecer.

16 Gérard Raulet, Le caractère destructeur. Messianisme, politique et esthétique chez Walter Benjamin, Paris, Aubier, 1997.

17 Irving Wohlfarth, 'Immer radikal, niemal konsequent...'. Zur theologischpolitischen Standortsbestimmung Walter Benjamin, in, Richard Faber \& Norbert Bolz, Königshausen, (eds e orgs.), Antike und Moderne. Zu Walter Benjamins 'Passagen', 1986, p. 116-137.

18 "Erst der Messias selbst vollendet alles historiche Geschehen, und zwar in dem Sinne, dass er dessen Beziehung auf das Messianische selbst erst erlöst, vollendet, schafft. Darum kann nichts Historisches von sich aus sich auf Messianisches beziehen wollen. Darum ist das Reich Gottes nicht das Telos der historischen Dynamis; es kann nicht zum Ziel gesetzt werden. Historisch gesehen ist es nicht Ziel, sondern Ende. Darum kann die Ordnung des Profanen nicht am 
Gedanken des Gottesreiches aufgbaut werden, darum hat die Theokratie keinen politischen sondern allein einen religiösen Sinn. Die politische Bedeutung der Theokratie mit aller Intensität geleugnet zu haben ist das grösste Verdienst von Blochs Geist der Utopie" (G.S. II-1, p. 203, trad. J.M.G.).

19 "Der Messias bricht die Geschichte ab; der Messias tritt nicht am Ende einer Entwicklung auf” (G.S. I-3, p. 1243, trad. J.M.G.).

20 Dialog uber die Religiosität der Gegenwart, G.S. II-1, p. 16 e ss.

21 Kapitalismus und Religion, G.S. VI, p. 100-111.

22 Ver Norbert Bolz, Auszug aus der entzauberten Welt, Fink Verlag, 1989; também, Uwe Steiner, Kapitalismus als Religion. Ammerkungen zu einem Fragment Walter Benjamins, Deutsche Vierteljahrschrift für Literaturwissenschaft und Geistesgeschichte, n. 1, 1998, p. 147-171.

23 A respeito dos anjos em W. Benjamin, ver, entre outros, Giorgio Agamben, Walter Benjamin und das Dämonische. Glück und geschichtliche Erlösung im Denken Benjamins, in Uwe Steiner (org.), Memoria. Walter Benjamin, Peter Lang Verlag, 1992; Jeanne Marie Gagnebin, O hino, a brisa e a tempestade: dos Anjos em Walter Benjamin, na coletânea Sete aulas sobre linguagem, memória e história, Imago, 1997.

24 Ver, a esse respeito, o artigo de Irving Wohlfarth, Märchen für Dialektiker. Walter Benjamin und sein bucklicht Männlein, in K. Doderer (ed.), Walter Benjamin und die Kinderliteratur, Weinheim, 1988, p. 121-176.

25 "Mein Denken verhält sich zur Theologie wie das Löschblatt zur Tinte. Es ist ganz von ihr vollgesogen. Ginge es aber nach dem Löschblatt, so würde nichts, was geschrieben ist, übrig bleiben" (G.S. I-3, p. 1235).

26 "Die befreite Prosa", ver o aparelho crítico das Thèses, G.S. I-3, p. 1235, 1238, 1239. O tema da Prosa, oriundo do romantismo alemão de Iena, é discutido na tese de doutorado de Benjamin, consagrada aos românticos. Ele volta, de modo decisivo, em sua variante hölderliniana, como nüchterne Pro$s a$, na Vorrede ao livro sobre o drama barroco, em que qualifica a especificidade do estilo filosófico. A sobriedade (holderliniana) e a universalidade (romântica) da prosa, é que fazem dela o emblema da linguagem libertada: livre da ênfase e da necessidade do belo estilo. A respeito da prosa em Benjamin, ver Giorgio Agamben, Langue et Histoire..., op. cit.; Márcio Seligmann-Silva, Prosa-Poesie. Unübersetzbarkeit, Berlim, 1996. Tese (doutorado). Freie Univesität, Institut für allgemeine und vergleichende Literaturwissenschaft.

27 "Der Messias wird erst kommen, wenn er nicht mehr nötig sein wird, er wird erst einen Tag nach seiner Ankunft kommen, er wird nicht am letzten Tag kommen, sondern am allerletzten." Hochzeitsvorbereitung auf dem Lande. Und andere Prosa aus dem Nachlass. Fischer, Gesammelte Werke, v. 6, p. 67, 3. Oktavheft, 4. Dez. 
28 Ver, a esse respeito, Stéphane Mosès, L'ange de l'histoire, Seuil, 1992, p. 181; J.M. Gagnebin, História e narração em Walter Benjamin, Perspectiva, 1994, p. 112.

29 Seria instrutivo comparar, no pensamento de Adorno e no de Benjamin, o uso respectivo das figuras messiânicas. Enquanto, no último - e tão belo fragmento de Minima moralia, a luz messiânica liberta o mundo porque permite ver, põe a descoberto as fissuras e feridas do mundo terrestre, em Benjamin, a alvorada messiânica deveria iluminar o mesmo mundo profano, porém, liso e feliz, do qual todas as feridas teriam sido apagadas, todas as deformidades, destruidas pelo fogo. Em Adorno, a redenção remeteria à alteridade e transcendência que possibilitam um conhecimento verdadeiro; em Benjamin, à imanência e, simultaneamente, ao aniquilamento.

30 Bernd Witte, depois de Scholem, salienta, que não é tanto na presença de um texto inaugural ou sistema de doutrinas que se assenta a Cabala, mas muito mais na necessidade do comentário e da escrita: "Aus dieser mystischen Ursprungstheorie folgt, dass in der Auffassung der Sprache als Schrift Wahrheit nicht in einem System gefunden werden kann, weil es kein Zentrum, keinen Sprecher mehr gibt, dessen Autorität sie verbürgte. Vielmehr muss sie im Kommentar je neu entfaltet, das heisst geschrieben werden. Denn die Offenbarung ist noch nicht vollendet, sondern wird sich erst in der Summe aller in der historischen Zeit zu schreibenden Kommentare erfüllen.” B. Witte, Walter Benjamin 'Einbahnstrasse'. Zwischen 'Passage de l'Opera' und 'Berlin Alexanderplatz' in Uwe Steiner (org. e ed.), Memoria. Walter Benjamin, Peter Lang Verlag, 1994, p. 268.

31 Paul Ricoeur, Du texte à l'action, Seuil, 1986, p. 129.

32 Dali a famosa frase: "Methode ist Umweg." No mesmo prefácio, G.S. I-1, p. 208.

33 Ao escrever seu célebre texto sobre o Ensaio como forma (Der Essay als Form, Noten zur Literatur II, Suhrkamp), Adorno se lembrará dessa Vorrede ao livro sobre o drama barroco.

34 Quarenta e nove ou sete vezes sete, imagem do infinito místico. Como eco teológico, a afirmação de J.L. Borges: "El concepto de texto definitivo no corresponde sino a la religión o al cansancio" [Las Versiones homericas, in Discusion, 1932 (Prosa completa, v. 1, p. 181, Ed. Bruguera)].

35 "Und wenn ich es denn in einem Wort aussprechen soll: ich habe nie anders forschen und denken können als in einem, wenn ich so sagen darf, theologischen Sinn - nämlich in Gemässheit der talmudischen Lehre von den neunundvierzig Sinnstufen jeder Thorastelle. Nun: Hierarchie des Sinnes hat meiner Erfahrung nach noch die abgegriffenste kommunistiche Plattitüde mehr als der heutige bürgerliche Tiefsinn, der immer nur den einen der 
Apologetik besitzt" (Carta de W. Benjamin a Max Rychner de 7 de abril de 1931, Briefe, Suhrkamp, 1966, p. 524).

36 Ver These XI, op. cit., p. 698.

RESUMO - NESTE ARTIGO retoma-se o debate a respeito de uma interpretação marxista ou de uma interpretação religiosa da filosofia de Walter Benjamin e propõe-se substituir essa alternativa por uma compreensão mais fina do papel da teologia nesse pensamento. A análise de alguns textos-chave de Benjamin (em particular Sobre o conceito de história e o Fragmento teológico-politico) permite interpretar a dimensão teológica como a recordação da incompletude e, simultaneamente, da pluralidade semântica da linguagem humana. Assim, o paradigma teológico introduz a uma teoria da textualidade e da leitura do mundo profano, em oposição a um paradigma religioso que tenta reverter o desencantamento do mundo.

RÉSUMÉ - CET ARTICLE reprend le débat au sujet de l'interprétation marxiste ou de l'interprétation religieuse de la philosophie de Walter Benjamin et propose de remplacer cette alternative par une compréhension plus fine du rôle de la théologie dans cette pensée. L'analyse de certains textes clefs de Benjamin (Sur le concept d'histoire et Fragment théologico-politique en particulier) permet d'interpréter la dimension theólogique comme le rappel de l'incomplétude et, simultanément, de la pluralité sémantique du langage humain. Ainsi le paradigme théologique introduit-il à une théorie de la textualité et de la lecture du monde profane, en opposition a un paradigme religieux Qui s'efforce de combattre le désenchantement du monde.

Jeanne Marie Gagnebin é professora de filosofia na PUC-SP e no Instituto de Estudos da Linguagem da Unicamp. Publicou, entre outros, História e narração em Walter Benjamin (Perspectiva, 1994) e Sete aulas sobre linguagem, memória e história (Imago, 1997).

Tradução de Jean Briant. O original em francês - Théologie et Messianisme dans la pensée de Walter Benjamin - encontra-se à disposição do leitor no IEA-USP para eventual consulta. 